\title{
Military claims laser dazzlers have "negligible" risk
}

$\mathrm{T}$ The Canadian Forces plans to equip its vehicles in Afghanistan by August with laser warning devices that carry a risk of blinding or damaging the eyesight of people who venture within a 12-metre secure zone.

"It's a very safe technology," says Major Paul Eagan, a doctor at the Occupational and Environmental Health Section, Directorate of Force Health Protection. "This is a logical extension of what the Canadian Forces already uses."

The 750 Visual Warning Technology systems that the Canadian Forces is buying are also known as "laser dazzlers." Soldiers will be trained to shine a dazzling green laser beam to warn people or vehicles approaching a Canadian convoy to stay away.

If people remain 12 metres outside the range of the laser systems - what the department calls the Nominal Occular Hazard Distance - there is no risk of eye damage, says Eagan.

"It's going to be a very bright light, like looking at the sun, or flash photography. It's going to be annoying, and your natural physiological response will be to quickly look away."

Any after-effect will resolve within seconds, Eagan says. "It would not be used within 12 metres."

The system is an alternative to firing on vehicles or people who are not deterred by shouted commands and hand signals, says Major Stéphane Dufour, project director for the Non-Lethal Laser Dazzler and Non-Lethal Capabilities. "At 12 metres, a person is already too close. I can tell you, if you keep coming after that beam has been flashed at you, you have bad intentions."

The danger occurs if the laser is used on someone within 12 metres. According to a Department of National Defence internal document entitled Safety Statement Concerning the NonLethal Laser Dazzler, "The type of injury to personnel who encounter hazardous levels of exposure will be a retinal burn. The severity of this burn, and its subsequent impact on the vision of the injured party may range from quite significant to virtually undetectable, but this is dependent on many factors and is best addressed by a medical specialist."

Someone would have to stare purposefully at the beam for more than 10 seconds to do that kind of damage, says Eagan. "But with all the fudge factors,

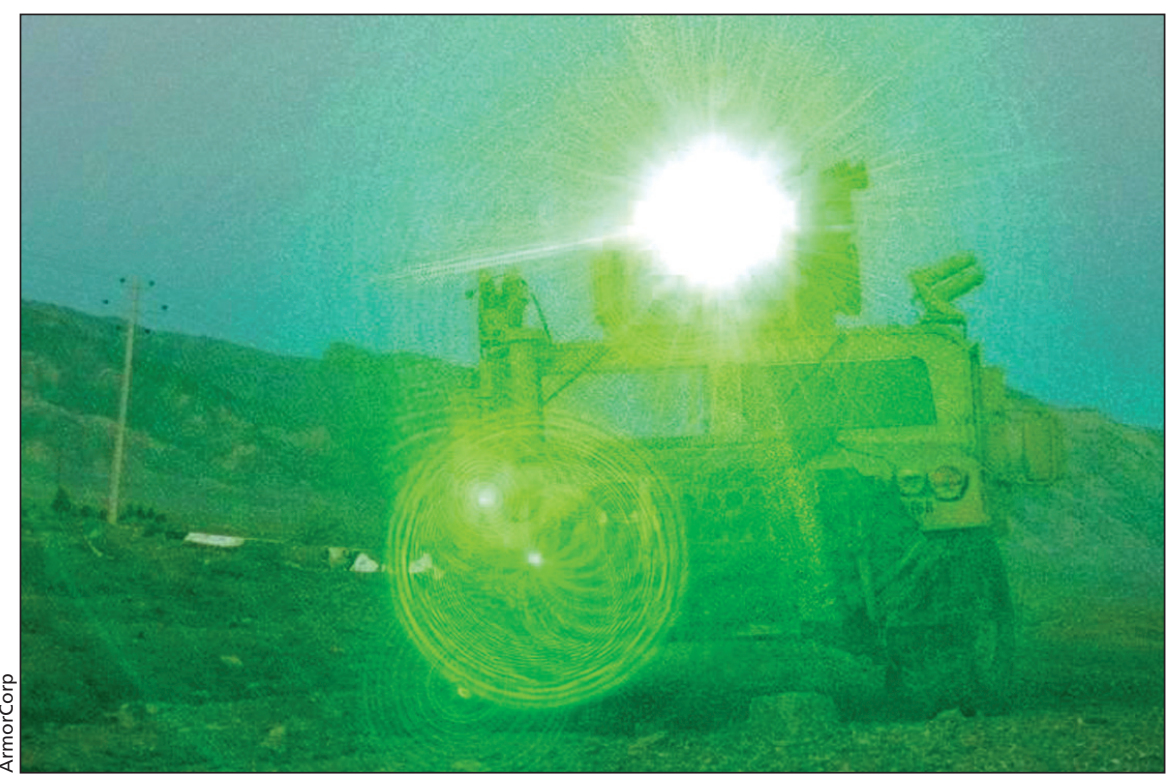

Canadian soldiers in Afghanistan are being equipped with laser dazzlers to dissuade people from venturing into secure zones. 
the redundancy, the safety and the training that the soldiers are going to get, the risk is negligible if not minimal."

In adopting laser dazzlers, the military hopes to reduce the number of incidents in which Canadian troops fire on innocent civilians who don't understand warnings to stop, says Dufour.

But as Anthony Salloum, the program director at the Rideau Institute, a nonprofit research, advocacy and consulting group points out, the fact dazzlers work well under controlled testing circumstances does not necessarily mean they'll translate easily into the field. "They're being controlled [by soldiers] in a theatre of war, where you can't control the conditions, or whether a target is 500 feet away from you or 10 feet away from you," he says. "It holds the potential to do permanent damage to people.'

Salloum is also concerned that a soldier handling the laser dazzler will be injured or thrown the wrong way and accidentally aim the device at a comrade.

"Another risk of employing the NLLDs [Non-Lethal Laser Dazzler] comes from the possibility of an accidental activation of the device, potentially exposing soldiers within the NOHD [Nominal Ocular Hazard Distance] to a hazardous level of radiation," the safety statement warns. It recommends training programs to mitigate that risk.
The Canadian Forces has a good training program and is equipping its soldiers with protective eyewear, says Eagan.

The United States is already using similar, but more powerful laser dazzlers in Iraq to warn and disorient people, and has trained the Iraqi population to stop or pull their vehicles over to the side of the road when they see the green light, says Dufour.

These devices are simply another tool in the Canadian Forces' arsenal, to help sort out innocent civilians from people who represent a threat, says Eagan. Laura Eggertson, CMAJ

DOI:10.1503/cmaj.090531

\section{Asbestos panel chair mystified by secrecy surrounding report}

Published at www.cmaj.ca on Apr.14. Updated May 4.

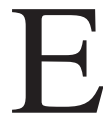
xposure to chrysotile asbestos has a strong relationship with lung cancer and some connection to other forms of cancer, according to reports written by a Health Canada-commissioned expert panel and released this spring.

The panel's conclusions essentially supported previous studies, and Chair Trevor Ogden is surprised that the government delayed the release of the reports for more than a year.

"Many people who read the reports will wonder what all the fuss is about," Ogden, editor-in-chief of the Annals of Occupational Hygiene, says in an email to CMAJ. "If they had been put on the Health Canada website a year ago they would have attracted little interest. This is a classic example of a document gaining disproportionate status by being kept secret."

Health Canada, however, claims the delay was necessary. In an email to CMAJ, Health Canada Media Relations Officer Christelle Legault says, "Health Canada took the time necessary to carefully review the findings of the report, and to consult other federal and provincial partners."

The 6-member expert panel met in

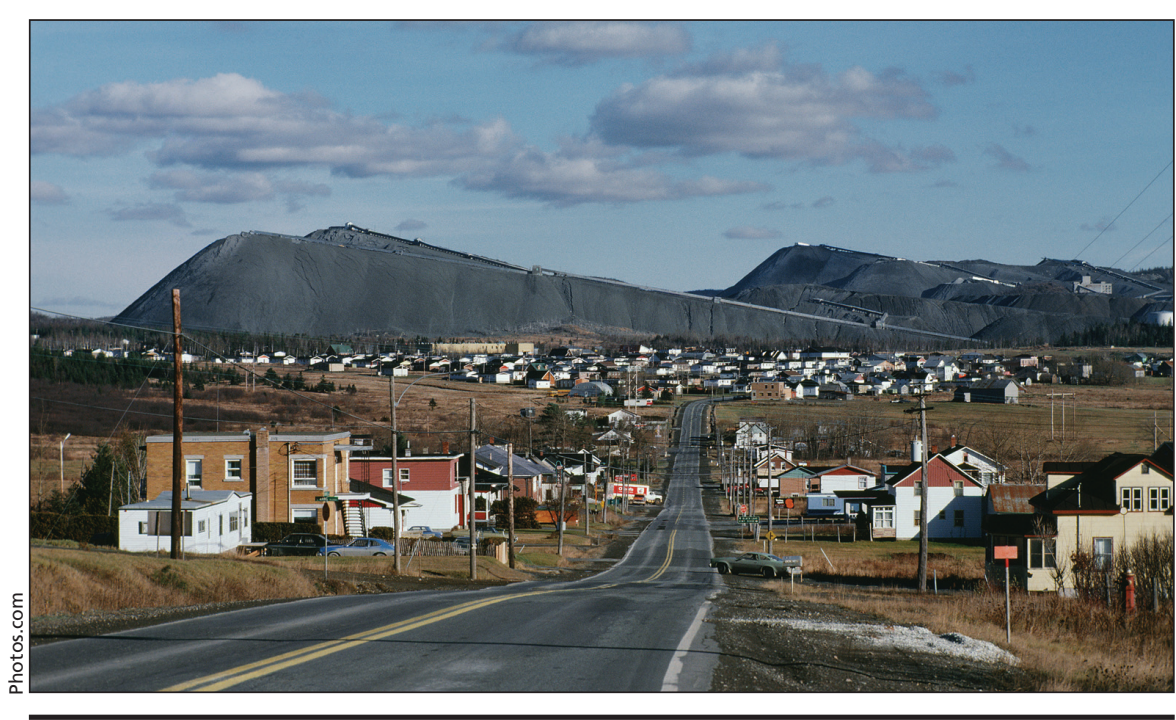

A special Health Canada panel concurred with 2 major epidemiological reviews that there is a link between chrysotile asbestos exposure and cancer. Those studies found that there was less disease than expected among people in the Quebec chrysotile mining industry but higher than expected among those involved in South Carolina textile manufacturing.

Montréal, Quebec, on Nov. 13-14, 2007 , to discuss the relationship between exposure to chrysotile asbestos and lung cancer, pleural mesothelioma and peritoneal mesothelioma. On Mar. 18, 2008, Ogden submitted 2 reports Summary Proceedings of the Panel Meetings and Consensus Statement and Summary — to Karen Lloyd, acting director general of the Safe Environments Programme at Health Canada's Healthy
Environments and Consumer Safety Branch.

In a letter accompanying the reports, Ogden wrote: "The Panel supported the approach of 2 major reviews, which give information on the relationship of the cancers to chrysotile exposure. Generally these show a strong relationship of exposure with lung cancer, but a much less certain relationship with mesothelioma."

In October 2008, Ogden voiced con- 